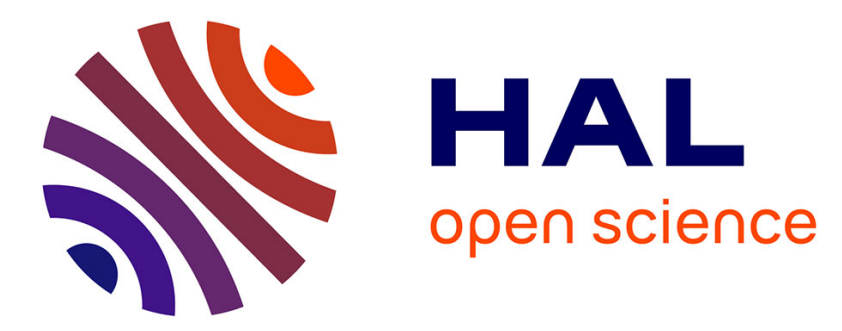

\title{
A wheat grain quantitative evaluation of vitreousness by light transmission analysis
}

Emna Chichti, Myriam Carrère, Matthieu George, Jean-Yves Delenne, Valerie Lullien-Pellerin

\section{- To cite this version:}

Emna Chichti, Myriam Carrère, Matthieu George, Jean-Yves Delenne, Valerie Lullien-Pellerin. A wheat grain quantitative evaluation of vitreousness by light transmission analysis. Journal of Cereal Science, 2018, 83, pp.58 - 62. 10.1016/j.jcs.2018.07.009 . hal-01904339

\section{HAL Id: hal-01904339 \\ https://hal.science/hal-01904339}

Submitted on 26 May 2020

HAL is a multi-disciplinary open access archive for the deposit and dissemination of scientific research documents, whether they are published or not. The documents may come from teaching and research institutions in France or abroad, or from public or private research centers.
L'archive ouverte pluridisciplinaire HAL, est destinée au dépôt et à la diffusion de documents scientifiques de niveau recherche, publiés ou non, émanant des établissements d'enseignement et de recherche français ou étrangers, des laboratoires publics ou privés. 


\section{Accepted Manuscript}

A wheat grain quantitative evaluation of vitreousness by light transmission analysis

Emna Chichti, Myriam Carrère, Matthieu George, Jean-Yves Delenne, Valérie LullienPellerin

PII:

S0733-5210(18)30287-X

DOI:

10.1016/j.jcs.2018.07.009

Reference: YJCRS 2603

To appear in: Journal of Cereal Science

Received Date: 9 April 2018

Revised Date: 29 June 2018

Accepted Date: 20 July 2018

Please cite this article as: Chichti, E., Carrère, M., George, M., Delenne, J.-Y., Lullien-Pellerin, Valé., A wheat grain quantitative evaluation of vitreousness by light transmission analysis, Journal of Cereal Science (2018), doi: 10.1016/j.jcs.2018.07.009.

This is a PDF file of an unedited manuscript that has been accepted for publication. As a service to our customers we are providing this early version of the manuscript. The manuscript will undergo copyediting, typesetting, and review of the resulting proof before it is published in its final form. Please note that during the production process errors may be discovered which could affect the content, and all legal disclaimers that apply to the journal pertain. 


\title{
A wheat grain quantitative evaluation of vitreousness by light transmission analysis
}

\author{
Emna Chichti ${ }^{\mathrm{a}, \mathrm{b}}$, Myriam Carrère ${ }^{\mathrm{c}}$, Matthieu George ${ }^{\mathrm{b}}$, Jean-Yves Delenne ${ }^{\mathrm{a}}$, \\ Valérie Lullien-Pellerin ${ }^{\mathrm{a}}$ \\ ${ }^{a}$ IATE, INRA, CIRAD, Montpellier SupAgro, Université de Montpellier, Montpellier, \\ France \\ ${ }^{b}$ Laboratoire Charles Coulomb (L2C), Université de Montpellier, CNRS, Montpellier, \\ France. \\ ${ }^{c}$ MOISA, INRA, CIHEAM-IAMM, CIRAD, Montpellier SupAgro, Univ Montpellier, \\ Montpellier, France
}

\begin{abstract}
Light transmission through wheat (T. aestivum L.) grain longitudinal cross sections of different thickness was used to study the endosperm microstructure and was shown to strictly follow a Beer-Lambert law allowing a non ambiguous quantification of the endosperm vitreousness. Therefore similar samples obtained from near-isogenic lines differing by hardness and grown in two distinct environments affecting their vitreousness were analyzed and confirmed the relationship between light transmission and the endosperm microstructure. In each sample, moreover analysis of light transmission within the different grain parts highlighted the greater compactness of the central endosperm cheeks in comparison with the distal and the proximal regions. These results helps a better understanding of the endosperm microstructure. Keywords: endosperm, hardness, microstructure, puroindoline, Triticum
\end{abstract}




\section{Introduction}

The protein-starch adhesion and the microstructure of the common wheat (Triticum aestivum L.) starchy endosperm were found to differ depending on genetic and environmental factors [1]. These factors are both found to affect the grain mechanical resistance i.e. endosperm hardness [2] and thus play a key role in grain milling behavior. Recently, an effort was made to experimentally clarify the role of these factors using genetically well-defined grains grown under different cultural conditions $[3,4]$. The main genetic locus controlling the starchy endosperm texture, called $H a$, was located on the short arm of chromosome 5D [5] where two important genes encoding specific proteins called puroindoline A (PINA) and puroindoline B (PINB), were found $[6,7]$. Presence of the wild-type alleles of both puroindoline genes (Pina-D1a/Pinb-D1a) leads to both functional PINA and PINB and results in a soft mechanical behavior, whereas mutation or deletion of one or both of the puroindoline genes was found to lead to a hard texture [7]. Moreover, translocation of the wild type puroindoline genes in a durum background [8], which lacks D genome, leads to mechanical resistance and similar characteristics to soft common wheat i.e. a higher production of the finest particles with low starch damage after milling $[9,10,11]$. Conversely, removal of the chromosome 5D distal part (which carries the puroindolines genes) in a soft hexaploid wheat led to hard vitreous grains [12].

Differences at the interface between protein and starch granules are suggested to explain the mechanical differences between soft and hard cultivars [13] and puroindolines are believed to affect the starch-protein adhesion. Indeed recent studies showed mechanical changes at the interface using near- 
isogenic lines differing only by the wild-type or mutated allele of the gene encoding PIN B [14].

Besides genetic factors, environmental conditions were found to affect the starchy endosperm appearance the so-called vitreousness [15] which is an optical property attributed to differences in endosperm porosity [16]. Grains are classified as mealy when the starchy endosperm is porous and appears white and floury, or as vitreous when it is transluscent and glassy. Vitreousness is generally estimated through examination of a number of grain cross-sections made with a Pohl grain cutter. However, this method is operator-dependent and time consuming. Therefore, other methods were recently developed for rapid classification of wheat grains depending on their vitreousness level. Transmitted light images were found allowing correct classification according to vitreousness even if percentages of accuracy relative to the visual inspection differ between authors $[17,18]$. Soft X-ray, dual energy X-ray or light reflectance coupled with image analysis were also found to be potentially efficient in the differentiation between vitreous and non-vitreous grains $[17,19,20]$. Near infrared hyper-spectral imaging was also used to satisfactory classified vitreous from non-vitreous grains [21, 22]. These classification methods are rapid and non-destructive. However, they are based on reference wheat samples which need to be well characterized and are only valid for grains which share the same characteristics as the references (grain geometric characteristics, tissue thickness, colors, hardness, etc.). These recent methods are hardly used to quantify the level of vitreousness as a function of the microstructure.

In the present work, we chose grains from two near-isogenic lines with a 
known profile of puroindoline alleles, encoding either native or mutated PINB

in order to fix hardness due to the genetic background, respectively soft or hard, and selected two different environments from a previous study [15] allowing obtaining contrasted levels of vitreousness for the starchy endosperm. Then, locally distinct regions within the endosperm were explored thanks to an original experimental assembly allowing measurement of transmitted light through grain cuts. It was thus possible to objectively compare the endosperm microstructure between the four wheat grain samples depending on genetic or environmental conditions, as well as within each type of sample depending on intra-grain location.

\section{Material and Methods}

\subsection{Wheat grains}

Near-isogenic lines (NIL) of Triticum aestivum L. were produced by Institut National de la Recherche Agronomique (INRA) and displayed either the wild-type Pinb-D1a or the mutated Pinb-D1b allele (leading to single amino acid change in PINB, Gly46Ser), which respectively conferred to grains the soft or the hard phenotype. They were derived from a cross after selection of the two allelic forms at the F6:F7 selfing generation (F7 siblings issued from the same F6 parent plant, construction and genetic similarity testing detailed in [3]). Grains from the two lines were cultivated in different locations in France, collected and cleaned to remove broken kernels or impurities and stored at $4^{\circ} \mathrm{C}$ before analysis. Percentage of vitreousness in each collected location was determined on grain cross sections $(n=500)$ obtained with a Pohl grain cutter (Versuchs and Lehranstalt, Brauerei, Berlin, Germany) 
depending on the proportion of glassy (translucent) area observed on the surface after visual analysis as described in [23]. Briefly, grains were classified into five groups according to the percentage of vitreous surface in the analyzed grains (i.e., grains that displayed less than $25 \%$ vitreousness were placed in the first group; those with around $25 \%$ vitreousness constituted the second group; and those with around 50, 75 or $100 \%$ vitreousness were placed in the third, fourth, and fifth groups, respectively). The number of grains in each class ( $N_{1}$ represents number of grains in class 1 , for example) was multiplied by the corresponding factor of vitreousness for that class, and the percentage of vitreousness in the grain sample was calculated according to the following equation: $\frac{N_{1} \times 0.00+N_{2} \times 0.25+N_{3} \times 0.50+N_{4} \times 0.75+N_{5} \times 1}{N_{1}+N_{2}+N_{3}+N_{4}+N_{5}}$, where the sum of the analyzed grains in each class was around 500. From a Student test the maximum error on this measurement was estimated, to be lower than 2 units. Grains harvested from two different locations (Cappelle $\left(50^{\circ} 29 N / 3^{\circ} 10 E\right)$ and Maule $\left.\left(48^{\circ} 54 N / 1^{\circ} 51 E\right)\right)$ were retained for this study as they were found to display contrasting endosperm vitreousness [15].

\subsubsection{Light transmission through endosperm samples}

Wheat kernels were abraded longitudinally from the back and the ventral sides with a 240 grit extra fine sandpaper (grit size $58.5 \mu \mathrm{m}$ ). Abraded grains were placed above a plate light (flat dome Light, LFX-100, CCS, Japan) that diffuses uniform white LED lighting (Figure 1a). In order to avoid straight light the plate light was covered with a black paper except at the kernel position. Then light transmission through grain cut was collected in the visible range using a $400 \mu \mathrm{m}$ diameter optical fiber and measured using a spectrometer (Ocean Optics USB 2000+XR extended range, FL, USA). 
The number of photons (Intensity in counts) per unit of time (100 ms) was obtained as a function of the wavelength (nm) between 400 and $800 \mathrm{~nm}$ and analyzed with the SpectraSuite software (Ocean Optics, Dunedin, Florida, USA). For each analyzed grain samples, thirty kernels were randomly selected and 3 grain locations were probed into the endosperm cheeks (Figure 1b): distal part (close to the brush), central, and proximal part (close to the germ). Therefore 180 measurement values were obtained for each wheat sample.

Figure 1: (a) Schematic representation of the experimental assembly used for the spectroscopic analysis of the grain microstructure. $\mathrm{h}$ is for the sample thickness (b) Example of the analyzed grains differing by vitreousness. Circles represent the six areas where the transmission spectra were collected into the starchy endosperm.

\subsection{Statistical analysis}

The statistical analysis, such as statistical tests and box-plots, were performed with R software (R Core Team (2016), R: A language and environment for statistical computing. R Foundation for Statistical Computing, Vienna, Austria. URL https://www.R-project.org/).

\section{Results}

Wheat samples were selected from a previous study [15].This study drove us to select grains with a defined puroindoline genome leading to either soft (native puroindoline a and b alleles) or hard (mutated puroindoline b) phenotype and grown in two contrasted environments resulting in different levels of vitreousness for the starchy endosperm. Wheat grains were characterized with a Pohl grain cutter as already described [23]. Considering the previous 
study [15] which described the vitreousness range within different wheat grain samples grown in two years and in seven different sites, samples displaying vitreousness below 40\%, were classified as mealy. Conversely, grains having a vitreousness score above $40 \%$ were considered as vitreous. This classification led us to identify four different grain samples defined by their genetic origin and vitreousness score (Soft Mealy, SM; Soft Vitreous, SV; Hard mealy, HM; Hard vitreous, HV) as summarized in Table 1.

\begin{tabular}{ccc}
\hline Grain samples & Genomic Pin profile & Vitreousness (\%) \\
\hline Soft Mealy (SM) & Pina-D1a/Pinb-D1a & $21.4 \pm 1.2$ \\
Soft Vitreous (SV) & Pina-D1a/Pinb-D1a & $48.2 \pm 1.6$ \\
Hard Mealy (HM) & Pina-D1a/Pinb-D1b & $23.1 \pm 1.1$ \\
Hard Vitreous (HV) & Pina-D1a/Pinb-D1b & $68.8 \pm 1.7$ \\
\hline
\end{tabular}

Table 1: Genomic profile and vitreousness of the wheat near-isogenic lines differing by hardness and displaying contrasted vitreousness (as determined with a Pohl grain cutter)

\subsection{Wheat grain endosperm vitreousness fits with a Beer Lambert law}

Wheat starchy endosperm is a cohesive granular material [24] composed of various phases among which starch, protein matrix and voids occupy most of the volume. In such a material the pores induce differences in light transmission resulting in various vitreousness. For this type of porous materials the strong variation in optical indexes, which constitute massive scattering events, should follow the Beer-Lambert law:

$$
I=I_{0} \exp (-\kappa h)
$$


where $I_{0}$ and $I$ are the incident and transmitted light beam respectively, $\kappa$ is an absorption coefficient which depends on the material, and $h$ is the thickness of the sample.

Therefore, this law directly relates the attenuation of light to the optical properties of the bulk microstructure. It is worth noting that $\kappa$ depends only on physical parameters without introducing any arbitrary variable.

To check the validity of this law, we performed light transmission measurement at the center of HV kernel cheek cross-sections with thicknesses varying from 0.9 to $1.8 \mathrm{~mm}$. Figure 2 shows the evolution of light transmission $T=I / I_{0}$ as a function of $h$ for three different samples. The results are well fitted by the Beer-Lambert law (in dashed line) with $\kappa=(1.13 \pm 0.50) \mathrm{mm}^{-1}$. The validity of the Beer-Lambert law to describe the transmission of light through the wheat endosperm gives way to characterize wheat propensity to transmit light with a sound physical parameter: the absorption coefficient. In the following, we chose instead to use the transmission coefficient $\tau=1 / \kappa$ which increases with vitreousness.

Figure 2: Evolution of the light transmission as a function of the grain thickness for three different HV samples (fit dashed line $T(h)=e^{-1.13 h}$ ). $\mathrm{h}$ is for the sample thickness.

The four wheat samples were then analyzed to determine $\tau$ (and thus the vitreousness) with a specific focus on both inter-grain samples or intragrain sample variability. We performed measurements on 30 randomly selected grains for each wheat samples (s) working at a carefully abraded fixed thickness $h_{s}=(1.58 \pm 0.14) \mathrm{mm}$. This thickness was chosen to get easily reproducible cross-sections with a good compromise between stiffness and sensitivity to transmission measurement. $\tau$ values were directly derived from 
the measurements of light transmission at this thickness, $T\left(h_{s}\right)$, using equation (2):

$$
\tau=\frac{-h_{s}}{\ln T\left(h_{s}\right)}
$$

\subsubsection{Inter wheat grain endosperm texture comparison}

Inter-grain comparison was performed by comparing the transmitted light between the same specific grain location in the different wheat samples (central areas of HV vs central areas of HM as an example). As far as the $\tau$ observations did not fulfill a Gaussian distribution, non-parametric tests were performed to compare samples. Wilcoxon-Mann-Whitney tests were implemented to compare the inter-grain observations (comparison of the median of the transmission coefficient $\tau$ from an identical location between different grain samples). Example of the inter-grain comparison corresponding to both of the endosperm central areas is illustrated in Figure 3. The represented boxplots highlighted the non-Gaussian and discontinuous distribution of the transmission coefficient within the different samples with a few number of grains displaying higher transmittance than the major part of the population in each case, clearly reflecting the natural sample heterogeneity.

The statistical results showed that mealy grains displayed the lowest light transmission coefficient, with no significant difference between soft and hard lines. On the opposite, vitreous grains exhibit higher transmission coefficients, which were influenced by the genetic origin of the grains. Indeed, HV grains present higher light transmission coefficients than SV grains (Figure 3).

For the different grain samples, the same comparison between transmis- 
Figure 3: Boxplot for intergrain comparison of the transmission coefficient $\tau$ for HV, HM, $\mathrm{SV}$ and SM in both of the central cheek endosperm. The graph summarizes the distribution of data as the following : boxes enclose $50 \%$ of the data $(n=60)$ with the median value for variables displayed as a line, boxes span from the first quartile to the third quartile and vertical lines display 1.5 times the interquartile distance from the box (with extreme values of whiskers $\left[\max \left(\tau_{\min }, Q 3-1.5(Q 3-Q 1)\right), \min \left(\tau_{\max }, Q 3+1.5(Q 3-Q 1)\right)\right]$ where $Q 1$, Q3, $\tau_{\max }$ and $\tau_{\min }$ are the first and third quantiles, and max and min are the measured values for each texture respectively). Outliers are positioned outside the box and the vertical lines. *, ** and ${ }^{* * *}$ indicate significance of the differences with $90 \%, 95 \%$ or 99 $\%$ confidence level respectively, with n.s.= non significant effect. Each measurement was labeled with a dot.

sion coefficient $\tau$ either in the proximal or distal regions reveal similar trends: 1) no statistical differences between mealy grains (low $\tau$ values), 2) light transmission decreases significantly in the order HV, SV and mealy (HM or $\mathrm{SM})$.

\subsection{Intra wheat grain endosperm texture comparison}

Comparison between measurements in the endosperm central areas with those in the proximal and distal extremities were also conducted to examine the intra-grain microstructure variability within each four wheat grain sample sets. Unilateral Wilcoxon signed rank tests were computed for these comparisons to determine if the median of the transmission coefficient $\tau$ measured at a specific endosperm location (central versus proximal and distal and distal versus proximal) within grains of a specific wheat sample was significantly higher or lower than the median value observed for both other locations. Within each wheat sample, the central areas transmitted significantly higher amount of light than distal endosperm positions (brush side), 
Figure 4: Boxplot for intragrain comparison of the transmission coefficient $\tau$ for HV, HM, $\mathrm{SV}$ and SM in the different endosperm regions : distal near the brush, central into the grain cheeks or proximal close to the germ. *, **, *** and n.s. as in Figure 3.

which transmitted more light than positions in the proximal regions (close to the germ), except for the HV grains where proximal and distal regions cannot be distinguished (Figure 4). However, within this HV sample, light transmission measurements through the different grains appeared the most variable as reflected by the boxplot height. Indeed vitreous samples clearly showed more data spreading corresponding to different endosperm organization within each grain whereas light transmission through each grain in mealy samples appeared more homogeneous.

\section{Discussion}

In this study, the endosperm microstructure was analyzed based on light transmission measurements. As grain endosperm organization was found to differ depending on the puroindoline allelic state which was suggested to play a role in starch-protein network adhesion [6], near-isogenic grains differing only by the puroindoline b allelic form (PinbD1a or PinbD1b) were used in order to well define the genetic background. These wheat samples were grown in two contrasted environments found to lead to distinct vitreousness level [15] and thus to different level of wheat endosperm porosity. Here, we demonstrated for the first time that vitreousness can be non-ambiguously quantified and compared from light transmission measurements through wheat samples displaying standardized thickness. As light transmission was found to follow a Beer-Lambert law, it is clearly the results of changes in the endosperm 
porosity as pores are known to scatter light. The statistical analysis showed that grains grown in an environment leading to mealy kernels but presenting distinct genetic background (as observed between mealy grains of distinct hardness, HM and SM) cannot be distinguished by light transmission because they display a high porosity level. Importance of the environment was also highlighted for grains within the same genetic background but grown in different locations that were found to display distinct vitreousness and thus light transmission (SM vs SV, HM vs HV). Consistency with these differences between wheat samples, presence of a pore network was shown to lead to weaker mechanical strength whatever the genetic background [3]. These results clearly highlight the importance of porosity or vitreousness characterization and of the identification of genetic background. Such a knowledge help us to get a more accurate understanding of the grain mechanical properties and thus the milling behavior as also previously noticed $[15,4]$. Furthermore, SV and HV wheat grains displayed distinct vitreousness scores and transmission coefficients even if they were grown in the same environment. Therefore for vitreous grains, presence of both wild-type puroindolines results in a significant decrease of $\tau$ revealing a more porous microstructure. This observation possibly suggests that light transmission, and thus vitreousness, is affected by the different genetic background of these wheat samples. Indeed, the soft line containing the wild-type puroindolines would have a lower starch-protein adhesion due to the higher puroindoline content at the starch granule surface in the endosperm $[25,26]$. The weak starch-protein adhesion could act as a network of internal microcracks. They may constitute another factor responsible for endosperm porosity that scatter the light and 
result in lower light transmission. Recently, Oury et al.[15] demonstrated, using similar genetic material that the soft near-isogenic lines never exceed a vitreousness level of $60 \%$ in comparison with the hard near-isogenic lines which were found to display a broader range of vitreousness levels (up to $80 \%$ ). Additionally a larger data spreading was found within the hard vitreous grain in accordance with the larger standard deviation observed in similar samples for mechanical properties [3]. Our results also match with modeling of the endosperm that also revealed a more important effect of changes in the adhesion between starch and the protein network (related to the presence of wild or mutated puroindoline alleles) in the case of low porosity [27]. Moreover, light transmission analysis also highlighted the heterogeneity in the endosperm microstructure depending on the location within the grain. The highest light transmission obtained in the central endosperm suggests a more compact organization in comparison with the distal or proximal regions respectively close to the brush or the germ extremities. These differences in compactness can be potentially related to the observed distinct behavior of the grain extremities against pathogen attack [28] or water, gibberelic acid and $\alpha$-amylase diffusion along imbibition/germination [29, 30].

\section{Conclusions}

In this study, we first demonstrated a Beer-Lambert relationship for light transmission through the endosperm allowing to quantify and compare endosperm microstructure depending on both genetic background and environmental conditions. We confirmed the role of the environment in endosperm porosity and revealed a more pronounced effect of the genetic background for 
grains with low vitreousness. Furthermore, local hetereogeneity within the endosperm was observed showing a more compact structure of the endosperm central region in accordance with our knowledge on grain physiology.

\section{Acknowledgement}

We would like to thank F.-X Oury (INRA, UMR GDEC Clermont Ferrand, Fr.) and M. Rousset (INRA, UMR GQE Le Moulon, Fr.) for providing the hard and soft near-isogenic lines. We also thank C. Michelet and colleagues from UFS (Paris, Fr.) for grain cultivation and A. Sadoudi (INRA, UMR IATE, Fr.) for his help in the light transmission analysis setting up. We are grateful to Montpellier University and the INRA-CEPIA department for the PhD grant of E. Chichti.

\section{References}

[1] K.-M. Turnbull, S. Rahman, Endosperm texture in wheat, Journal of Cereal Science 36 (2002) 327-337.

[2] Y. Haddad, J. Benet, J. Delenne, A. Mermet, J. Abecassis, Rheological behaviour of wheat endospermproposal for classification based on the rheological characteristics of endosperm test samples, Journal of Cereal Science 34 (2001) 105-113.

[3] V. Greffeuille, J. Abecassis, M. Rousset, F.-X. Oury, A. Faye, C. B. LHelgouach, V. Lullien-Pellerin, Grain characterization and milling behaviour of near-isogenic lines differing by hardness, Theoretical and Applied Genetics 114 (2006) 1-12. 
[4] F.-X. Oury, P. Lasme, C. Michelet, A. Dubat, O. Gardet, E. Heumez, B. Rolland, M. Rousset, J. Abecassis, C. B. LHelgouach, et al., Bread wheat milling behavior: effects of genetic and environmental factors, and modeling using grain mechanical resistance traits, Theoretical and Applied Genetics 130 (2017) 929-950.

[5] N. Chantret, J. Salse, F. Sabot, S. Rahman, A. Bellec, B. Laubin, I. Dubois, C. Dossat, P. Sourdille, P. Joudrier, et al., Molecular basis of evolutionary events that shaped the hardness locus in diploid and polyploid wheat species (Triticum and Aegilops), The Plant Cell 17 (2005) 1033-1045.

[6] M. Bhave, C. F. Morris, Molecular genetics of puroindolines and related genes: allelic diversity in wheat and other grasses, Plant Molecular Biology 66 (2008) 205-219.

[7] C. F. Morris, Puroindolines: the molecular genetic basis of wheat grain hardness, Plant Molecular Biology 48 (2002) 633-647.

[8] C. F. Morris, M. C. Simeone, G. King, D. Lafiandra, Transfer of soft kernel texture from Triticum aestivum to durum wheat, Triticum turgidum ssp. durum, Crop Science 51 (2011) 114-122.

[9] C. Morris, J. Casper, A. Kiszonas, E. Fuerst, J. Murray, M. Simeone, D. Lafiandra, Soft kernel durum wheat a new bakery ingredient?, Cereal Foods World 60 (2015) 76-83.

[10] J. C. Murray, A. M. Kiszonas, J. Wilson, C. F. Morris, Effect of soft 
kernel texture on the milling properties of soft durum wheat, Cereal Chemistry 93 (2016) 513-517.

[11] K. Heinze, A. Kiszonas, J. Murray, C. Morris, V. Lullien-Pellerin, Puroindoline genes introduced into durum wheat reduce milling energy and change milling behavior similar to soft common wheats, Journal of Cereal Science 71 (2016) 183-189.

[12] C. F. Morris, B. S. Beecher, The distal portion of the short arm of wheat (Triticum aestivum L.) chromosome 5D controls endosperm vitreosity and grain hardness, Theoretical and Applied Genetics 125 (2012) 247254 .

[13] K. Barlow, H. Simmonds, M. Vesk, The nature of the starch-protein interface in wheat endosperm, Cereal Chemistry 50 (1973) 443-454.

[14] E. Chichti, M. George, J.-Y. Delenne, V. Lullien-Pellerin, Changes in the starch-protein interface depending on common wheat grain hardness revealed using atomic force microscopy, Plant Science 239 (2015) 1-8.

[15] F.-X. Oury, P. Lasme, C. Michelet, M. Rousset, J. Abecassis, V. LullienPellerin, Relationships between wheat grain physical characteristics studied through near-isogenic lines with distinct puroindoline-b allele, Theoretical and Applied Genetics 128 (2015) 913-929.

[16] B. Dobraszczyk, M. Whitworth, J. Vincent, A. Khan, Single kernel wheat hardness and fracture properties in relation to density and the modelling of fracture in wheat endosperm, Journal of Cereal Science 35 (2002) 245-263. 
[17] S. Neethirajan, C. Karunakaran, S. Symons, D. Jayas, Classification of vitreousness in durum wheat using soft x-rays and transmitted light images, Computers and Electronics in Agriculture 53 (2006) 71-78.

[18] G. Venora, O. Grillo, R. Saccone, Quality assessment of durum wheat storage centres in Sicily: evaluation of vitreous, starchy and shrunken kernels using an image analysis system, Journal of Cereal Science 49 (2009) 429-440.

[19] S. Neethirajan, D. Jayas, C. Karunakaran, Dual energy x-ray image analysis for classifying vitreousness in durum wheat, Postharvest Biology and Technology 45 (2007) 381-384.

[20] F. Xie, T. Pearson, F. E. Dowell, N. Zhang, Detecting vitreous wheat kernels using reflectance and transmittance image analysis, Cereal Chemistry 81 (2004) 594-597.

[21] N. Gorretta, J. Roger, M. Aubert, V. Bellon-Maurel, F. Campan, P. Roumet, Determining vitreousness of durum wheat kernels using near infrared hyperspectral imaging, Journal of Near Infrared Spectroscopy 14 (2006) 231-239.

[22] S. Serranti, D. Cesare, G. Bonifazi, The development of a hyperspectral imaging method for the detection of Fusarium-damaged, yellow berry and vitreous Italian durum wheat kernels, Biosystems Engineering 115 (2013) 20-30.

[23] P. Lasme, F.-X. Oury, C. Michelet, J. Abécassis, F. Mabille, C. B. L'Helgouac'h, V. Lullien-Pellerin, A study of puroindoline b gene in- 
volvement in the milling behavior of hard-type common wheats, Cereal Chemistry 89 (2012) 44-51.

[24] V. Topin, F. Radjai, J.-Y. Delenne, A. Sadoudi, F. Mabille, Wheat endosperm as a cohesive granular material, Journal of Cereal Science 47 (2008) 347-356.

[25] G. Igrejas, T. Gaborit, F.-X. Oury, H. Chiron, D. Marion, G. Branlard, Genetic and environmental effects on puroindoline-a and puroindolineb content and their relationship to technological properties in French bread wheats, Journal of Cereal Science 34 (2001) 37-47.

[26] L. Gazza, F. Taddei, M. Corbellini, P. Cacciatori, N. Pogna, Genetic and environmental factors affecting grain texture in common wheat, Journal of Cereal Science 47 (2008) 52-58.

[27] E. Chichti, V. Lullien-Pellerin, M. George, F. Radjai, R. Affes, J.-Y. Delenne, Bottom-up model for understanding the effects of wheat endosperm microstructure on its mechanical strength, Journal of Food Engineering 190 (2016) 40-47.

[28] R. W. Skadsen, T. M. Hohn, Use of Fusarium graminearum transformed with gfp to follow infection patterns in barley and arabidopsis, Physiological and Molecular Plant Pathology 64 (2004) 45-53.

[29] J. R. Rathjen, E. V. Strounina, D. J. Mares, Water movement into dormant and non-dormant wheat (Triticum aestivum L.) grains, Journal of Experimental Botany 60 (2009) 1619-1631. 
376

377

378

[30] F. J. Bruggeman, K. R. Libbenga, B. Duijn, The diffusive transport of gibberellins and abscisic acid through the aleurone layer of germinating barley grain: a mathematical model, Planta 214 (2001) 89-96. 

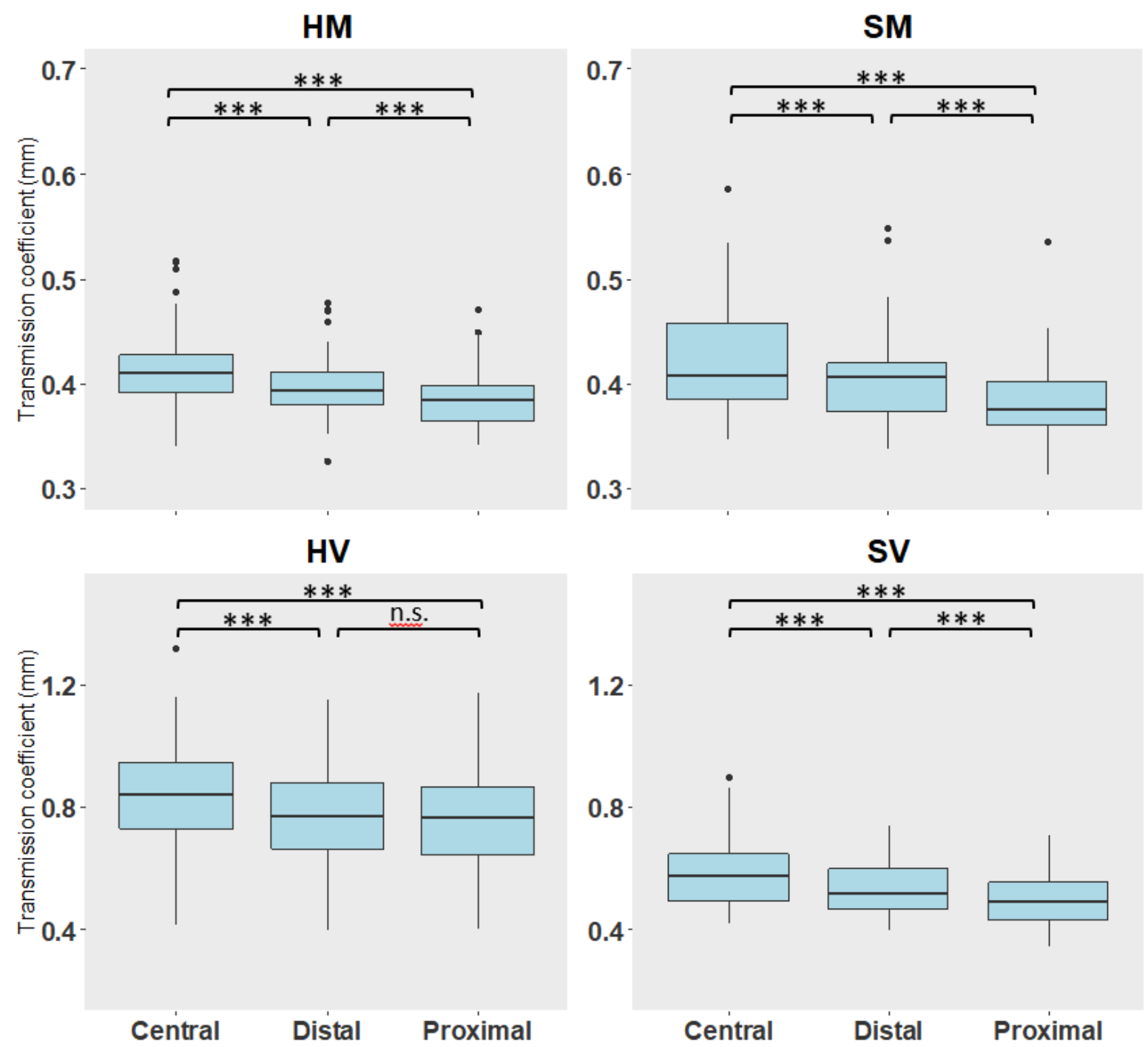

1.2
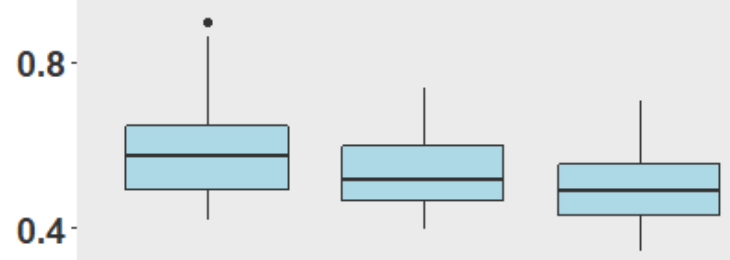

Central Distal Proximal 


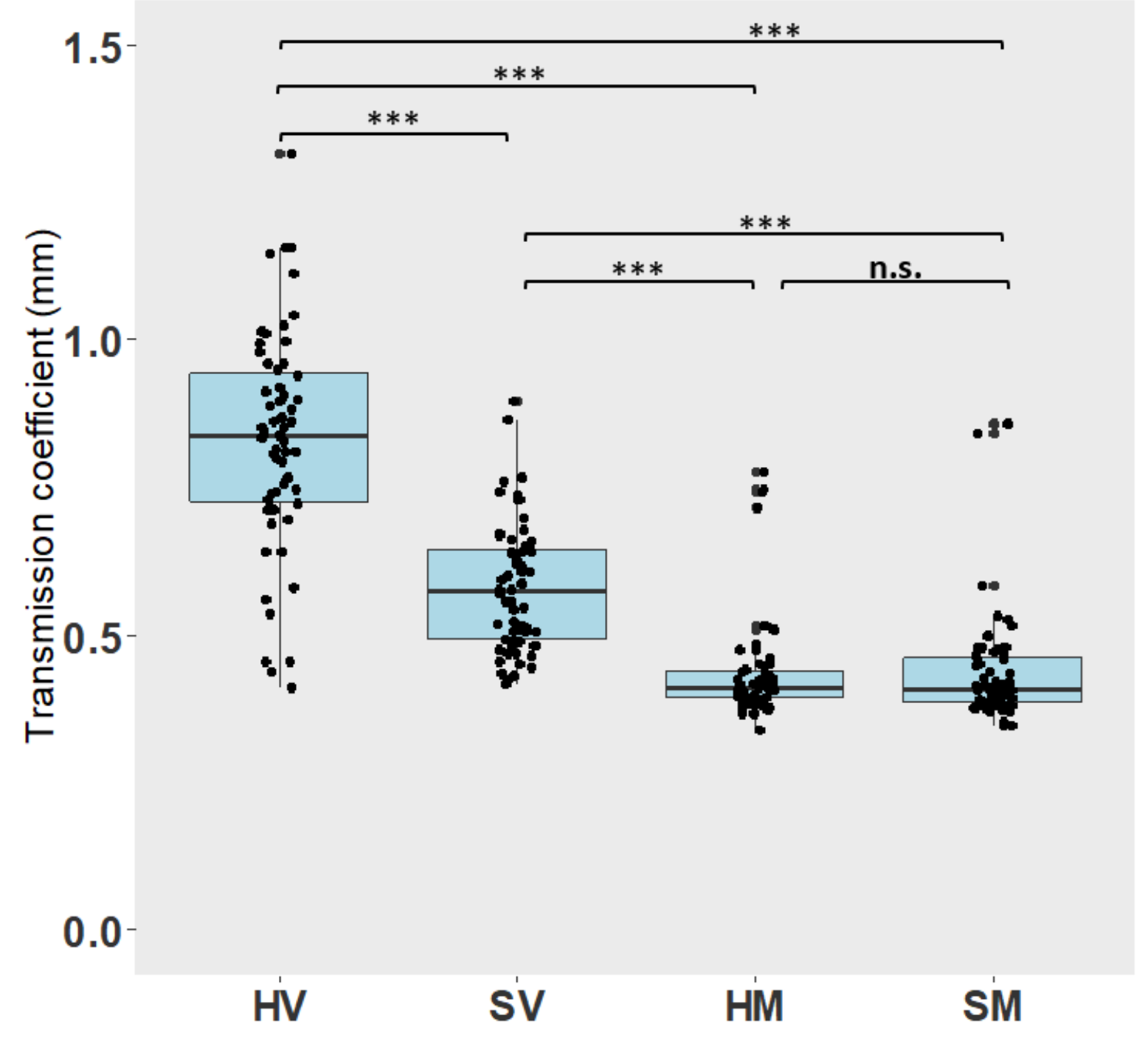




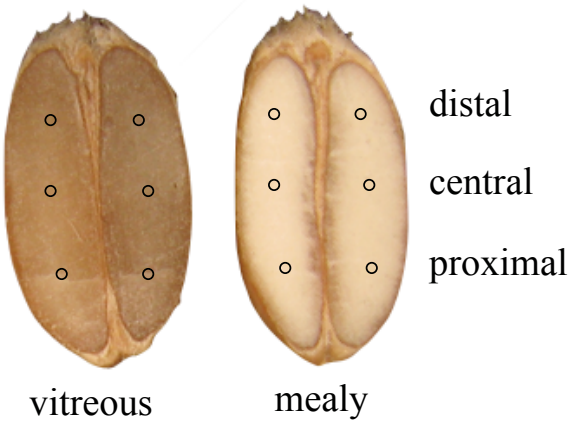


Highlights:

- Light transmission through the wheat endosperm follows a Beer-Lambert law

- Similar endosperm light transmission was found in grains displaying low porosity

- The highest transmittance was found with vitreous grains from hard genotype

- The proximal or distal part of the endosperm was more porous than the center 